Article

\title{
Effect of Membrane Type for the Treatment of Organized Industrial Zone (OIZ) Wastewater with a Membrane Bioreactor (MBR): Batch Experiments
}

\author{
Oktay Özkan and İbrahim Uyanık * \\ Erciyes University, Faculty of Engineering, Department of Environmental Engineering, Melikgazi, Kayseri 38039, \\ Turkey; ozkan@erciyes.edu.tr \\ * Correspondence: iuyanik@erciyes.edu.tr; Tel.: +90-352-207-6666-7498
}

Received: 11 July 2017; Accepted: 1 August 2017; Published: 4 August 2017

\begin{abstract}
Organized industrial zone (OIZ) wastewater is a mixed wastewater that is contributed by both municipal use and from different industrial sectors. Since MBR has advantages over conventional treatment plants, membrane types and fouling become the most important parameters in the treatment of this kind of wastewater. In this study, six different membrane types were used to find the most suitable membrane with the least resistivity to fouling. Three different microfiltration (MF) and ultrafiltration (UF) membranes were operated to estimate their (i) membrane, (ii) cake, (iii) pore, and (iv) total resistances. The highest total resistance was observed in a polyethersulfone (PES) membrane $\left(3.8 \times 10^{10} \mathrm{~m}^{-1}\right)$, while the lowest one was a UF polyvinylidene fluoride (PVDF) membrane with approximately 20 times lower resistance than the highest one. PVDF membranes showed lower total resistances than PES membranes. An MF or a $250 \mathrm{kDa}$ UF membrane could be operated long-term in a membrane bioreactor with the least fouling potential.
\end{abstract}

Keywords: MBR; membrane selection; resistance; membrane fouling

\section{Introduction}

Environmental management of the industrial activities could be better controlled when they are organized in an isolated area in developing countries [1-3]. Centralized and organized industrial zones are common in Turkey, the number of which exceeded 250 [4]. Only one third of these organized industrial zones (OIZs) have their own wastewater treatment plant (WWTP) [4]. The characteristics of the wastewater of OIZs are very different from each other, as their wastewater originates from different sectors. However, the wastewater is similar to municipal wastewater in terms of biological degradation in that their wastewater also comes from the daily water consumption of workers. Industrial water contamination must be controlled, since it affects not only the health of living organisms but also indirectly affects the economy $[5,6]$.

Membrane bioreactors (MBRs) are needed for wastewater to conform to regulations that require high-quality effluents in both developed and developing countries [7,8]. Regardless of the effluent quality of the MBR, it is a good pre-treatment option before a reuse alternative. However, MBR treatment has some technical issues or limitations in operations, and membrane fouling is one of them $[8,9]$.

The fouling problem has been investigated in several studies. Most of the studies are linked with microbial community for the reason of the fouling $[10,11]$. In a study of MBR treating textile wastewater, microbial composition has been found to be affected by reactor operating conditions [12]. The study further maintains that microbial community may have an impact on biofouling, and each MBR has its own characteristics. Therefore, microbial community structure is the main reason for fouling, regardless of biodegradable type of wastewater to treat. In another study, factors affecting 
the biofouling mechanism were reviewed and fouling factors discussed [13]. Biofouling increases as mixed liquor suspended solids (MLSS), organic loading rate (OLR), and food to microorganisms $(\mathrm{F} / \mathrm{M})$ ratio are high, and dissolved oxygen concentration, hydraulic retention time (HRT), and sludge retention time (SRT) are low [14]. High salinity and temperature also increase the soluble microbial products and decrease membrane permeability. Although system parameters in MBR can be changed, it still may not be easy to stabilize all the parameters in desired levels. Therefore, membrane fouling is inevitable, but it could be minimized.

While MBR batch studies [15,16] were conducted for the removal of some micropollutants, membrane types were investigated in other studies $[17,18]$. One study on natural organic matter (NOM) removal investigated using hollowfiber (HF) membranes-two hydrophobic and one hydrophilic. Hydrophobic ones fouled more quickly because hydrophilic compounds formed a gel layer on the surface of the membrane [17]. Another study on membrane type and materials was conducted using three different MF membranes with the same pore sizes. Track-etched polyester (PETE) membrane was the worst one, while the other two were nearly the same in terms of flux decline [18].

The membrane type operated in MBR did not vary widely, since almost $50 \%$ of the membranes used in commercial MBR products were polyvinylidene difluoride (PVDF) from among three membrane configurations; namely, flat sheet (FS), hollowfiber (HF), and multitube (MT) [8]. Polyethersulfone (PES) membranes are the second-most-used membranes, and are used only for FS modules. FS module was compared with HF module in a study showing that it could be operated for 6 months without external cleaning compared to HF module (4 months) [19].

Membrane resistances of the MBR studies have been estimated only for specific resistances in the literature for the prediction of fouling behavior [20-22]. One study shows that cake resistance plays a major role in filtration efficiency [23]. Another one shows that the fouling is irreversible, as the blocking resistance is the major one. Similarly, when cake resistance is the major one, fouling is reversible [22]. However, a pre-study of the membrane resistances is not performed before a long-term operation in MBR.

Selection of membrane type is a hard task for industrial wastewater, since fouling is one of the most important parameters for long-term operations [8]. In this study, membrane types were investigated according to their resistances to an organized industrial zone (OIZ) wastewater using six different MF and UF membranes in MBR.

\section{Materials and Methods}

\subsection{Membrane Bioreactor (MBR)}

The reactor used in the study is made of plexiglass with a $20 \mathrm{~L}$ of active volume. Real wastewater and activated sludge from the Kayseri organized industrial zone (KOIZ) WWTP were initially fed to the reactor. Then, it was continuously monitored with a programmable logic control (PLC) system as for the dissolved oxygen (DO), oxidation-reduction potential (ORP), $\mathrm{pH}$, temperature, pressure, water level, and flux. Basic influent and effluent parameters of the reactor for one month of operation with a 10 kDa ultrafiltration (UF) FS membrane are given in Table 1.

Wastewater fed to the MBR was from the primary sedimentation tank of the WWTP. Operational parameters of the MBR were stable during each day when the modules were operated. MLSS was $7.2 \pm 0.2 \mathrm{~g} / \mathrm{L}$, while hydraulic retention time (HRT) was $40 \mathrm{~h}$. A peristaltic pump (Watson-Marlow, Sci-Q 300) with constant speed was used in all experiments to vacuum the filtrate from the reactor. Wastewater of KOIZ mainly comes from textile, paper, recycling, and metal industries, including the wastewater of daily use of 7000 workers, which turns the character of the wastewater into a high-strength domestic wastewater in terms of biodegradability. 
Table 1. Membrane bioreactor (MBR) influent and effluent parameters.

\begin{tabular}{ccc}
\hline Parameters & Influent & Effluent \\
\hline $\mathrm{pH}$ & $7.1 \pm 0.36$ & $7.9 \pm 0.4$ \\
Electrical conductivity (EC) (ms/cm) & $4.8 \pm 0.92$ & $5.1 \pm 1.1$ \\
Chemical oxygen demand (COD) $(\mathrm{mg} / \mathrm{L})$ & $471 \pm 228$ & $39.5 \pm 22.3$ \\
Biochemical oxygen demand (BOD) $(\mathrm{mg} / \mathrm{L})$ & $211 \pm 75$ & 0 \\
$\mathrm{NO}_{2}-\mathrm{N}(\mathrm{mg} / \mathrm{L})$ & 0 & 0 \\
$\mathrm{NO}_{3}-\mathrm{N}(\mathrm{mg} / \mathrm{L})$ & $<0.01$ & $3.5 \pm 2.1$ \\
\hline
\end{tabular}

\subsection{Membranes}

Flat sheet membranes used in the study are given in Table 2. Membrane materials are PES and PVDF (three of each), and membrane types were three microfiltration (MF) and three UF with different pore sizes and molecular weight cutoff (MWCO) values. Membranes are given with increasing pore sizes.

Table 2. Properties of microfiltration (MF) and ultrafiltration (UF) membranes. PES: polyethersulfone; PVDF: polyvinylidene difluoride.

\begin{tabular}{cccc}
\hline Membrane Type & Brand & Pore Size $(\mu \mathrm{m})$ & Membrane Material \\
\hline MP005 & Microdyn-Nadir & 0.05 & PES \\
UF 4 kDa & Philos & 0.07 & PES \\
UF 10 kDa & Philos & 0.1 & PES \\
MV02 & Microdyn-Nadir & 0.2 & PVDF \\
MF & Philos & 0.24 & PVDF \\
UF 250 kDa & Philos & 0.44 & PVDF \\
\hline
\end{tabular}

\subsection{Experimental Procedure}

Flat sheet membrane modules used in the study were prepared in the laboratory with an area of $285 \mathrm{~cm}^{2}$. Firstly, the modules were submerged into distilled water and vacuumed for $30 \mathrm{~min}$ while recording flux and pressure at every min. Secondly, the modules were submerged into the MBR and operated for one day $(24 \mathrm{~h})$ without relaxation/backwashing. Lastly, the modules were cleaned only physically and vacuumed again for $30 \mathrm{~min}$ with new distilled water to calculate the membrane resistances. Physical cleaning was performed by removing cake layer with a soft sponge and by washing it externally under running tap water. The membrane resistance $(R)$ for each of the resistances can be calculated as:

$$
R=\Delta P \cdot \mu^{-1} \cdot J_{s S}{ }^{-1}
$$

where $R$ is the filtration resistance $\left(\mathrm{m}^{-1}\right), \Delta P$ is the pressure difference between steady state and the beginning (Pa), $\mu$ is the permeate viscosity $(\mathrm{Pa} \cdot \mathrm{s})$, and $\mathrm{J}_{\mathrm{ss}}$ is the steady-state flux $\left(\mathrm{m}^{3} / \mathrm{m}^{2} \cdot \mathrm{s}\right)$. From the above experimental procedure, $R_{\mathrm{m}}$ can be calculated as membrane resistance from the distilled water filtration and $R_{\mathrm{t}}$ can be calculated as total resistance from MBR filtration. After cleaning the module with deionized water, the resistance is $R_{\mathrm{m}}+R_{\mathrm{p}}$, where $R_{\mathrm{p}}$ is the pore resistance. The cake resistance, $R_{\mathrm{c}}$, can be calculated from the difference of steps 1 and 3 as $R_{\mathrm{t}}-\left(R_{\mathrm{m}}+R_{\mathrm{p}}\right)$. All experiments were conducted daily, with a total time of 6 days. Figure 1 is illustrated for an easy understanding of the experimental procedure. 


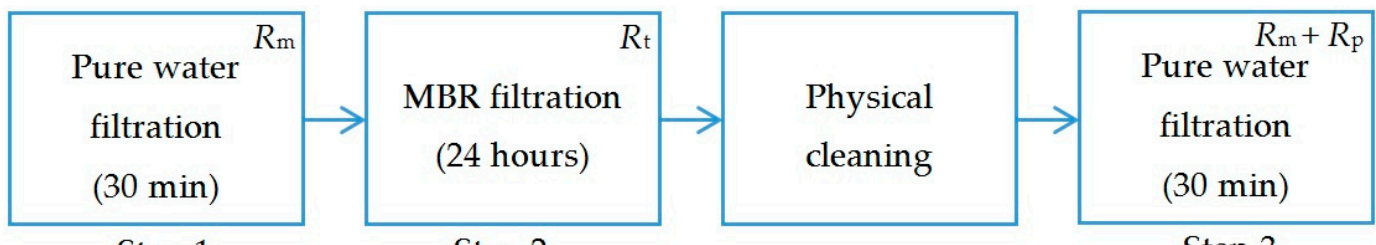

Step 1

Step 2

Step 3

Figure 1. Flow diagram of the experimental procedure.

\subsection{Analytical Methods}

All parameters were analyzed according to Standard Methods [24]. In the MBR, all parameters mentioned above are measured online. Permeate analysis was made using a HACH multimeter ( $\mathrm{pH}$, temperature, electrical conductivity $(\mathrm{EC})$ ), while turbidity analysis was made with a $\mathrm{HACH}$ 2100AN laboratory turbidimeter. Chemical oxygen demands (CODs) of the permeate samples were analyzed using titrimetric method (Standard Methods $5220 \mathrm{C}$ ). Membrane fluxes were measured as $\mathrm{L} \cdot \mathrm{m}^{-2} \cdot \mathrm{h}^{-1}(\mathrm{LMH})$.

\section{Results and Discussion}

Basic water quality parameters of the effluent of membranes operated in the MBR were not significantly different from each other, as shown in Table 3. The treated water had high EC, low COD, and low turbidity. Although this wastewater had higher organic and pollutant loading rate, these values are consistent with other MBR studies treating municipal wastewater treatment plants in terms of average COD and turbidity removal $[25,26]$. Since the membranes are MF and UF membranes, EC values do not reduce as expected.

Table 3. Permeate analysis results after MBR operation.

\begin{tabular}{ccccc}
\hline Membrane & Effluent $\mathbf{p H}$ & $\mathbf{E C}(\mathbf{m s} / \mathbf{c m})$ & COD $(\mathbf{m g} / \mathrm{L})$ & Turbidity (NTU) \\
\hline MP005 & $8.10 \pm 0.12$ & $4.06 \pm 0.08$ & $19 \pm 7$ & $0.42 \pm 0.25$ \\
UF 4 k & $8.19 \pm 0.24$ & $4.23 \pm 0.06$ & $32 \pm 11$ & $0.36 \pm 0.18$ \\
UF 10 k & $8.10 \pm 0.09$ & $4.62 \pm 0.11$ & $38 \pm 4$ & $0.72 \pm 0.09$ \\
MV02 & $8.16 \pm 0.17$ & $4.41 \pm 0.10$ & $66 \pm 14$ & $0.88 \pm 0.13$ \\
MF & $8.01 \pm 0.05$ & $5.02 \pm 0.27$ & $67 \pm 9$ & $0.96 \pm 0.07$ \\
UF 250 k & $8.41 \pm 0.10$ & $4.65 \pm 0.18$ & $21 \pm 16$ & $0.21 \pm 0.16$ \\
\hline
\end{tabular}

\subsection{Resistances}

Membrane, pore, and cake resistances of the membranes are given in Figure 2. PVDF membranes showed lowest membrane $\left(R_{\mathrm{m}}\right)$ and pore resistances $\left(R_{\mathrm{p}}\right)$, while PES membranes demonstrated high pore resistance. The highest pore-sized membrane showed the lowest pore resistance. Membrane resistances $\left(R_{\mathrm{m}}\right)$ of the PVDF membranes were lower than PES membranes because of the hydrophobicity of the membrane structure. An inverse relationship with the $R_{\mathrm{m}}$ of the PES membranes and their pore sizes may be originated from the membrane fabrication, as the contact angles differ. The UF $10 \mathrm{kDa}$ membrane with $0.1 \mu$ pore size showed the highest membrane resistance with distilled water.

MP005 (PES) with the lowest pore-sized membrane indicated approximately 60\% more cake resistivity in MBR. The hydrophobicity of this membrane causes organic matter to form a cake layer on the membrane surface. This type of membrane is not a good choice because of a very high potential of a cake layer being formed. Additionally, this cake layer may block the pores of the PES membranes. 


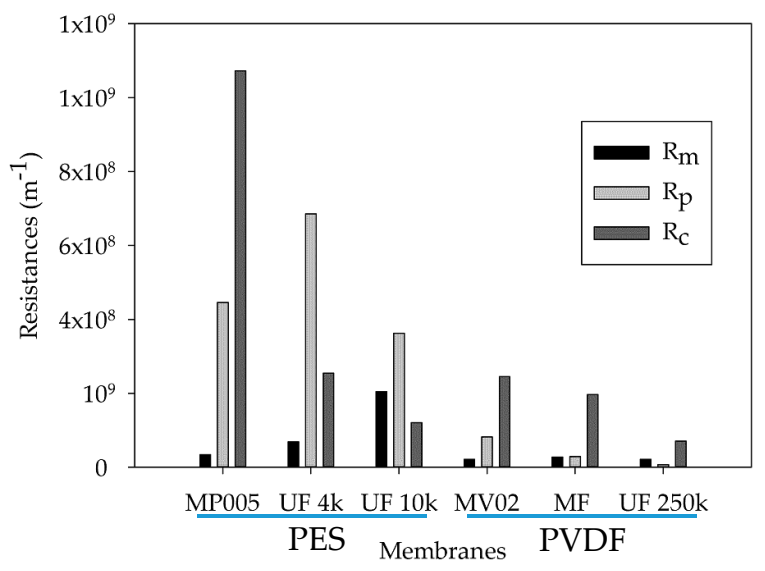

Figure 2. Membrane, pore, and cake resistances of the membranes.

Another significant result in Figure 2 is the pore resistances, which are very high in PES membranes compared to PVDF ones. The cake resistances of PDVF membranes were higher than the pore resistances. This data indicates that the cake layer is removed by physical washing. However, pore resistances of PES membranes are higher than the cake resistances, except for MP005 membrane, which indicates that the pores of the membranes fouled irreversibly. This type of fouling can only be cleaned by chemical cleaning agents, but not physically. This finding is consistent with previous studies. Pore blocking is found to be irreversible, while cake blocking is easily removed by simple backwashing, and irreversible blocking may be formed due to the organic macromolecules [22]. However, in another study, PVDF membranes showed a removable fouling character, with flux being nearly the same as before the operation [27]. Other studies of cake and pore blocking of the membranes also showed that pore blocking and cake formation are the dominant fouling mechanisms in PES membranes [28].

Although the UF $4 \mathrm{kDa}$ membrane showed the highest pore resistance, it had lower total resistance (Figure 3) than the MP005 membrane, both of which are the same material (PES). This could be due to both the pore sizes and the manufacturing processes of different membrane suppliers. Total resistances of the membranes were inversely proportional to their pore sizes. The lowest total resistance was seen in the UF $250 \mathrm{kDa}$ membrane with the highest pore size. However, that alignment was not reflected on the water quality, as it has better COD and turbidity removal than the other membranes. The effect of pore sizes is discussed in another study, which suggested that larger pore sizes exhibit faster flux decline, while having better flux recovery in different UF membranes [21]. The study also showed that hydrophobicity is the second unwanted property in terms of fouling. Membranes with lower MWCO and high hydrophobicity demonstrated the worst performance, as in the current study, with the hydrophobic membrane (MP005) with the smallest pore size.

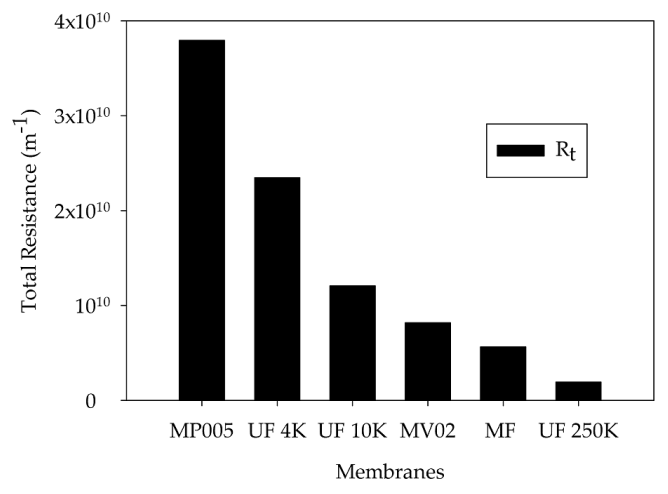

Figure 3. Total resistances of the membranes. 


\subsection{Flux Pressure Profiles}

Flux pressure profiles of the membranes are shown in Figures 4 and 5 for only MP005 and UF $250 \mathrm{kDa}$, respectively. These membranes showed the highest and lowest total resistances, respectively. For the MP005 membrane, flux rapidly declined in $15 \mathrm{~min}$ in MBR (Step 2), while it was stable in distilled water before and after the operation in the MBR. Almost no pressure rise was observed in distilled water filtration (Step 1). However, it reached steady state at 0.8 bar for both the MBR and after the cleaning operation (Step 3). A rapid rise in pressure indicated that the membrane surface was clogged by soluble foulants such as soluble microbial products (SMPs). This was also indicated in a fouling study conducted in a submerged MBR [29].

However, flux was almost recovered after simple physical cleaning of the MP005 membrane. This is due to the cake layer formed on the membrane surface in MBR operation, as shown in Figure 2 (MP005 membrane has the highest cake resistance). Fouling of this membrane can be related to high pressure during filtration caused by cake formation. Cake layer on the membrane surface acts as another filter layer to increase the pressure and the resistance. The easier cleaning of the cake layer can be related to the hydrophobic nature of the membrane. In a membrane fouling study, it is suggested that increasing surface hydrophilicity cannot mitigate membrane fouling in MBRs [29]. High zeta potential and roughness of membranes alleviate membrane fouling, as stated earlier [29]. Therefore, the PES membranes used in this study are not proper for an MBR filtration of OIZ wastewater, as they show high potential of fouling.

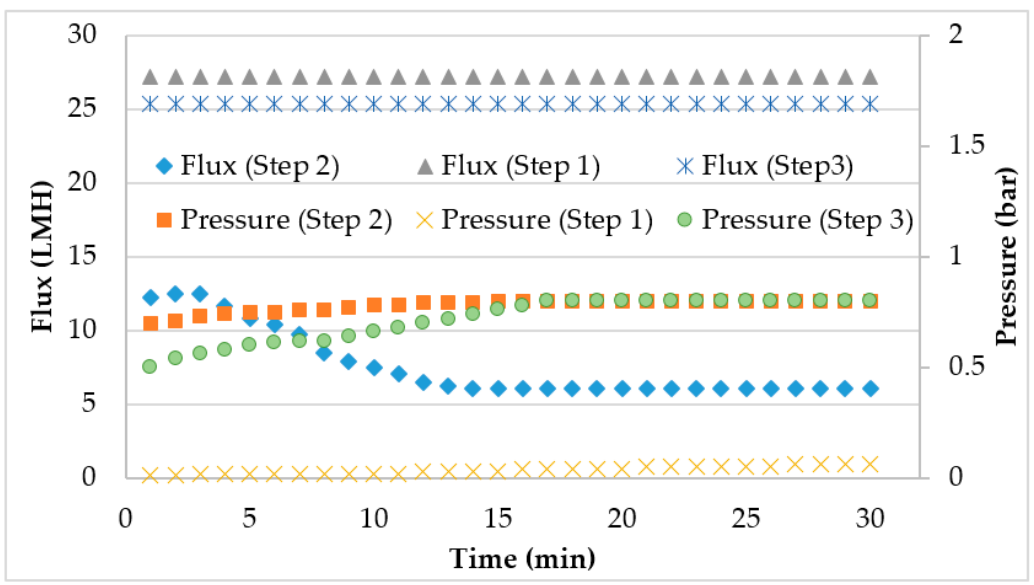

Figure 4. Flux pressure profile of MP005 membrane. LMH: $\mathrm{L} \cdot \mathrm{m}^{-2} \cdot \mathrm{h}^{-1}$.

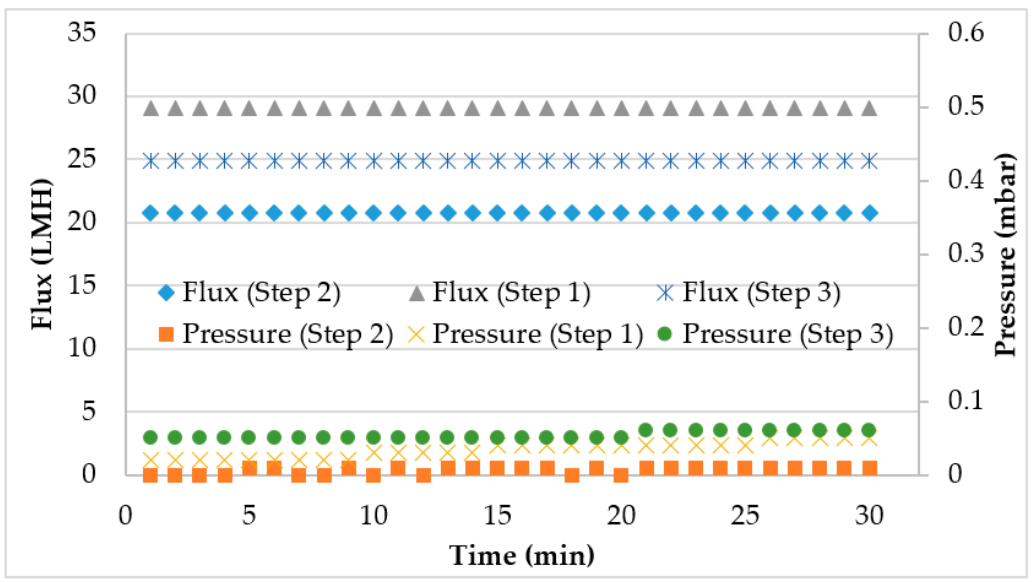

Figure 5. Flux pressure profile of UF 250 kDa membrane. 
The UF $250 \mathrm{kDa}$ membrane, with the best performance in the current study, showed little or no pressure rise in all steps. This membrane also had little or no flux decline when operated in the MBR (Figure 5). MBR flux of this membrane reached as high as $25 \mathrm{LMH}$, while the worst one (MP005) declined from about $12 \mathrm{LMH}$ to $6 \mathrm{LMH}$.

Resistances and flux-pressure profiles of PVDF membranes showed less resistivity to OIZ wastewater than PES membranes. Both membrane types are known to be hydrophobic; however, the PVDF membranes used in this study seem to be less hydrophobic than PES membranes. The membrane with the best performance was a UF membrane (MWCO of $250 \mathrm{kDa}$ ), which has hydrophobic nature and PVDF material. Therefore, hydrophobicity may not be a fouling parameter in the MBR filtration of OIZ wastewater.

\section{Conclusions}

MBR treatment of industrial wastewater is not a novel subject; however choosing the right membrane in a long-term operation is essential for maintenance, investment, and operation costs. Membrane resistivity is the key parameter for the treatment of mixed industrial wastewater in terms of fouling for operation. This study showed that for a high-strength industrial zone wastewater, membranes with high pore size showed low resistance with PVDF membranes. A UF membrane which had a $250 \mathrm{kDa}$ MWCO value and highest pore sized membrane demonstrated the best performance in terms of resistance. Water quality of this permeate was also much better than other types of membranes. Tertiary treatment of this wastewater for reuse will be investigated with different nanofiltration (NF) and reverse osmosis $(\mathrm{RO})$ membranes in our further studies.

Acknowledgments: This study was funded by The Scientific and Technological Research Council of Turkey (TUBITAK) (Project Number: 114Y521). We also thank the Istanbul Technical University National Research Center on Membrane Technologies (ITU-MEMTEK).

Author Contributions: Oktay Özkan conceived and designed the experiments; İbrahim Uyanık performed the experiments, analyzed the data, provided membrane materials, and wrote the paper.

Conflicts of Interest: The authors declare no conflict of interest.

\section{References}

1. Yaylali-Abanuz, G. Heavy metal contamination of surface soil around gebze industrial area, Turkey. Microchem. J. 2011, 99, 82-92. [CrossRef]

2. Komarovska, A.; Ustinovichius, L.; Shevchenko, G.; Nazarko, L. Multicriteria evaluation of commercial industrial zone development. Int. J. Strateg. Prop. Manag. 2015, 19, 84-95. [CrossRef]

3. Dwivedi, A.K.; Vankar, P.S.; Sahu, R.S. Geochemical trends of heavy metal in aquifer system of kanpur industrial zone, uttar pradesh (India): A case study. Environ. Earth Sci. 2015, 73, 7287-7296. [CrossRef]

4. Turkish Republic Science, Industry, and Technology Ministry. Organized Industrial Zones. 2014. Available online: https:/ / osbbs.sanayi.gov.tr/citylist.aspx (accessed on 1 May 2017).

5. Rahman, M.A.; Rusteberg, B.; Uddin, M.S.; Saada, M.A.; Rabi, A.; Sauter, M. Impact assessment and multicriteria decision analysis of alternative managed aquifer recharge strategies based on treated wastewater in northern Gaza. Water 2014, 6, 3807-3827. [CrossRef]

6. Choi, Y.-Y.; Baek, S.-R.; Kim, J.-I.; Choi, J.-W.; Hur, J.; Lee, T.-U.; Park, C.-J.; Lee, B.J. Characteristics and biodegradability of wastewater organic matter in municipal wastewater treatment plants collecting domestic wastewater and industrial discharge. Water 2017, 9, 409. [CrossRef]

7. Judd, S. The MBR Book: Principles and Applications of Membrane Bioreactors for Water and Wastewater Treatment, 2nd ed.; IWA Press: London, UK, 2011.

8. Judd, S. The status of industrial and municipal effluent treatment with membrane bioreactor technology. Chem. Eng. J. 2015, 305, 37-45. [CrossRef]

9. Jeon, S.; Rajabzadeh, S.; Okamura, R.; Ishigami, T.; Hasegawa, S.; Kato, N.; Matsuyama, H. The effect of membrane material and surface pore size on the fouling properties of submerged membranes. Water 2016, 8, 602 . [CrossRef] 
10. Ahmed, Z.; Cho, J.; Lim, B.R.; Song, K.G.; Ahn, K.H. Effects of sludge retention time on membrane fouling and microbial community structure in a membrane bioreactor. J. Membr. Sci. 2007, 287, 211-218. [CrossRef]

11. Sato, Y.; Hori, T.; Navarro, R.R.; Habe, H.; Yanagishita, H.; Ogata, A. Fine-scale monitoring of shifts in microbial community composition after high organic loading in a pilot-scale membrane bioreactor. J. Biosci. Bioeng. 2016, 121, 550-556. [CrossRef] [PubMed]

12. Yurtsever, A.; Sahinkaya, E.; Aktaş, Ö.; Uçar, D.; Çinar, Ö.; Wang, Z. Performances of anaerobic and aerobic membrane bioreactors for the treatment of synthetic textile wastewater. Bioresour. Technol. 2015, 192, 564-573. [CrossRef] [PubMed]

13. Guo, W.; Ngo, H.-H.; Li, J. A mini-review on membrane fouling. Bioresour. Technol. 2012, 122, $27-34$. [CrossRef] [PubMed]

14. Vanysacker, L.; Declerck, P.; Bilad, M.R.; Vankelecom, I.F.J. Biofouling on microfiltration membranes in mbrs: Role of membrane type and microbial community. J. Membr. Sci. 2014, 453, 394-401. [CrossRef]

15. Joss, A.; Zabczynski, S.; Göbel, A.; Hoffmann, B.; Löffler, D.; McArdell, C.S.; Ternes, T.A.; Thomsen, A.; Siegrist, H. Biological degradation of pharmaceuticals in municipal wastewater treatment: Proposing a classification scheme. Water Res. 2006, 40, 1686-1696. [CrossRef] [PubMed]

16. Radjenović, J.; Petrović, M.; Barceló, D. Fate and distribution of pharmaceuticals in wastewater and sewage sludge of the conventional activated sludge (cas) and advanced membrane bioreactor (mbr) treatment. Water Res. 2009, 43, 831-841. [CrossRef] [PubMed]

17. Gray, S.R.; Ritchie, C.B.; Tran, T.; Bolto, B.A. Effect of nom characteristics and membrane type on microfiltration performance. Water Res. 2007, 41, 3833-3841. [CrossRef] [PubMed]

18. Choi, J.-H.; Ng, H.Y. Effect of membrane type and material on performance of a submerged membrane bioreactor. Chemosphere 2008, 71, 853-859. [CrossRef] [PubMed]

19. Bodík, I.; Blšt'áková, A.; Dančová, L.; Sedláček, S. Comparison of flat-sheet and hollow-fiber membrane modules in municipal wastewater treatment. Pol. J. Environ. Stud. 2009, 18, 331-340.

20. Wang, X.-M.; Li, X.-Y.; Huang, X. Membrane fouling in a submerged membrane bioreactor (smbr): Characterisation of the sludge cake and its high filtration resistance. Sep. Purif. Technol. 2007, 52, 439-445. [CrossRef]

21. Qu, F.; Liang, H.; Zhou, J.; Nan, J.; Shao, S.; Zhang, J.; Li, G. Ultrafiltration membrane fouling caused by extracellular organic matter (eom) from microcystis aeruginosa: Effects of membrane pore size and surface hydrophobicity. J. Membr. Sci. 2014, 449, 58-66. [CrossRef]

22. Jiang, T.; Kennedy, M.D.; van der Meer, W.G.; Vanrolleghem, P.A.; Schippers, J.C. The role of blocking and cake filtration in MBR fouling. Desalination 2003, 157, 335-343. [CrossRef]

23. Chu, P.H.; Li, X. Membrane fouling in a membrane bioreactor (MBR): Sludge cake formation and fouling characteristics. Biotechnol. Bioeng. 2005, 90, 323-331.

24. Clesceri, L.S.; Greenberg, A.E.; Trussell, R.R. Standard Methods for the Examination of Water and Wastewater, 17th ed.; American Public Health Association: Washington, DC, USA, 1998.

25. Farias, E.L.; Howe, K.J.; Thomson, B.M. Effect of membrane bioreactor solids retention time on reverse osmosis membrane fouling for wastewater reuse. Water Res. 2014, 49, 53-61. [CrossRef] [PubMed]

26. Raffin, M.; Germain, E.; Judd, S. Wastewater polishing using membrane technology: A review of existing installations. Environ. Technol. 2013, 34, 617-627. [CrossRef] [PubMed]

27. Uyanık, İ.; Özkan, O.; Koyuncu, İ. Nf-ro membrane performance for treating the effluent of an organized industrial zone wastewater treatment plant: Effect of different uf types. Water 2017, 9, 506. [CrossRef]

28. Lim, A.L.; Bai, R. Membrane fouling and cleaning in microfiltration of activated sludge wastewater. J. Membr. Sci. 2003, 216, 279-290. [CrossRef]

29. Zhang, M.; Liao, B.; Zhou, X.; He, Y.; Hong, H.; Lin, H.; Chen, J. Effects of hydrophilicity/hydrophobicity of membrane on membrane fouling in a submerged membrane bioreactor. Bioresour. Technol. 2015, 175, 59-67. [CrossRef] [PubMed]

(C) 2017 by the authors. Licensee MDPI, Basel, Switzerland. This article is an open access article distributed under the terms and conditions of the Creative Commons Attribution (CC BY) license (http:/ / creativecommons.org/licenses/by/4.0/). 